\title{
Ultrasonographic evaluation of depth-width ratio (D/W) of benign and malignant mammary tumors in dogs
}

\author{
Michihito TAGAWA ${ }^{1)}$, Eiichi KANAI ${ }^{2) *}$, Genya $\mathrm{SHIMBO}^{1)}$, Mikiya $\mathrm{KANO}^{3)}$ and Hideki KAYANUMA ${ }^{2)}$ \\ ${ }^{1)}$ Veterinary Medical Center, Department of Clinical Veterinary Medicine, Obihiro University of Agriculture and Veterinary Medicine, \\ Inada, Obihiro, Hokkaido 080-8555, Japan \\ ${ }^{2)}$ Department of Veterinary Radiology, Veterinary Medicine, Azabu University, Sagamihara, Kanagawa 252-5201, Japan \\ 3) Kano Animal Hospital, Tsurugashima, Saitama 350-2222, Japan
}

(Received 31 July 2015/Accepted 10 November 2015/Published online in J-STAGE 21 November 2015)

ABSTRACT. Depth-width ratio (D/W) is the only quantitative item in the criteria recommended by the Japanese Ultrasound Society for the evaluation of breast tumors in humans. However, the usefulness of the D/W has not been evaluated in dogs. Eighty-six mammary masses in 34 female dogs underwent ultrasonographic examination to determine the D/W and other characteristics. Results of ultrasonographic and histopathologic examinations were compared. The $\mathrm{D} / \mathrm{W}$ of malignant tumors was significantly greater than that of benign tumors, and it had a sensitivity of $56.3 \%$ and a specificity of $92.9 \%$ for the diagnosis of malignancy when the threshold of D/W was 0.7 . In addition, irregular margin, polymorphous shape and heterogeneous internal echographic characteristics were correlated with malignancy.

KEY WORDS: canine, depth-width ratio, mammary tumor, ultrasound

doi: 10.1292/jvms.15-0456; J. Vet. Med. Sci. 78(3): 521-524, 2016

Mammary gland tumors are the most common type of neoplasia in dogs, and the prevalence of these tumors is approximately $50 \%$ of all tumors in female dogs [13]. Although preoperative cytological examinations are useful in ruling out other differentials, including mast cell tumors, it is hard to differentiate benign from malignant lesions with this method [13].

Ultrasonography is a noninvasive and safe technique and is becoming widespread in practice [7]. In human medicine, the role of ultrasound in the detection and diagnosis of breast pathology has been expanded, and sonography is routinely used as an adjunct to X-ray mammography [12]. The depthwidth ratio $(\mathrm{D} / \mathrm{W})$ was first established by the Japanese Ultrasound Society in 1989 as a useful diagnostic tool in differentiating malignant from benign mammary tumors, because it is the only quantitative item in several criteria used to evaluate breast masses by the society $[4,5]$. In Japanese literature, $\mathrm{D} / \mathrm{W}$ has a sensitivity of $64.5 \%$ and a specificity of $70.5 \%$ for the diagnosis of malignancy [6]. However, ultrasonographic evaluation of mammary gland tumors using $\mathrm{D} / \mathrm{W}$ has not until now been utilized in veterinary medicine.

Previous studies have reported on ultrasonographic findings of the canine mammary mass, including differences in the ultrasonographic characteristics between benign and malignant mammary tumors [7]. Ultrasonography has also been used to assess the tissue composition and vascularity of canine mammary tumors, and Doppler evaluation may

*Correspondence to: Kanai, E., Department of Veterinary Radiology, Veterinary Medicine, Azabu University, Sagamihara, Kanagawa 252-5201, Japan. e-mail: kanai@azabu-u.ac.jp

(C)2016 The Japanese Society of Veterinary Science

This is an open-access article distributed under the terms of the Creative Commons Attribution Non-Commercial No Derivatives (by-nc-nd) License $<$ http://creativecommons.org/licenses/by-nc-nd/4.0/>. be helpful to predict malignancy $[1,10]$. Although it has been suggested that mammary tumors in dogs have similar ultrasonographic features to mammary tumors in humans [8], the technique is not used routinely to evaluate mammary masses in dogs. Our objective in this study was to assess the efficacy of the D/W and ultrasonographic characteristics for differentiation between benign and malignant mammary tumors in dogs.

Eighty-six mammary tumors in 34 female dogs that were admitted to the Kano Animal Hospital for surgical treatment from 2010 through 2011 were examined in this study. Seventeen dogs had a single tumor, and seventeen dogs had multiple tumors. Of the dogs with multiple mammary masses, 3 presented with 2 tumors, 5 with 3, 3 with 4, 2 with 5, 3 with 6 and the rest one dog with 8 masses. Before surgical excision, tumor size including length, width and height was measured by a vernier micrometer.

The ultrasound examination was performed with a 10.0 $\mathrm{MHz}$ convex probe using NEMIO SSA-550A ultrasound equipment (TOSHIBA MEDICAL SYSTEMS, Ohtawara, Japan). The definition of $\mathrm{D} / \mathrm{W}$ is the division of the depth by the transverse diameter of the mass [15]. The transverse diameter is the maximum diameter of the mass on ultrasound and is measured in the plane running parallel to the skin. The depth diameter is the vertical length of the mass perpendicular to the transverse diameter (Fig. 1). The margins (regular or irregular), shape (oval or polymorphous), internal echogenicity (hypoechoic, isoechoic or hyperechoic, as compared with surrounding fat tissue), and internal (homogeneous or heterogeneous) and posterior (enhancement, unchanged or shadowing) echographic characteristics of the mass were also evaluated, as described in human medicine $[3,5]$. All analyses of the recorded ultrasound images were performed by a single observer (M. T.), and informed consent was obtained from all the patients before data sampling. 

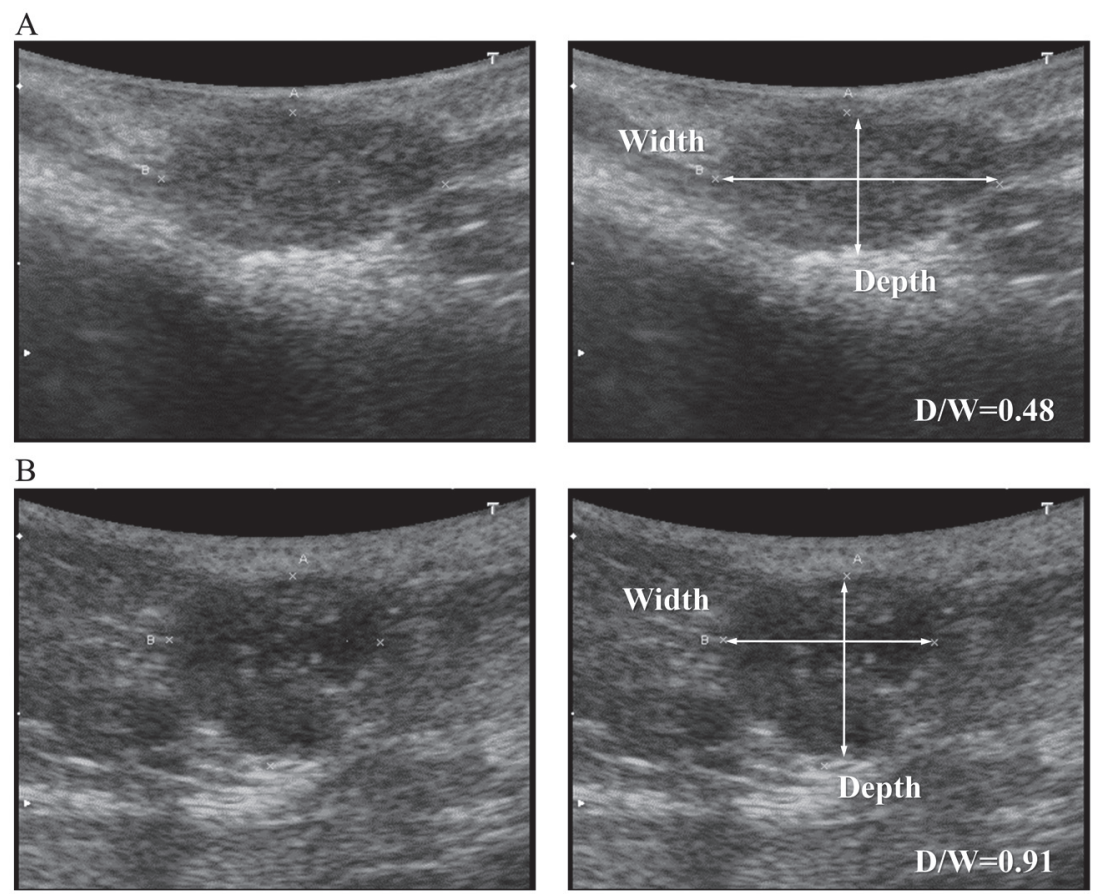

Fig. 1. Ultrasonography images of the benign (A; adenoma) and malignant (B; carcinoma) mammary tumors and the measurement of $\mathrm{D} / \mathrm{W}$. The $\mathrm{D} / \mathrm{W}$ of a mass is the division of depth by transverse diameter of the mass.

The mammary masses were excised under general anesthesia and examined histologically by a board-certified pathologist at a commercial laboratory. The ultrasonographic findings were compared between the benign and malignant tumors diagnosed on histological examination. Categorical variables, such as margins, shape and echogenicity, were analyzed by chi-square test. Continuous variables, such as $\mathrm{D} / \mathrm{W}$ and tumor size, were analyzed by the Student's $t$-test. $P<0.05$ was considered statistically significant.

By histological examination results, 16, 66 and 4 masses were classified as malignant tumors, benign tumors and lobular hyperplasia, respectively (Table 1). Multiple tumors showed both malignant and benign tumors, and malignant tumors occurred in concurrence with benign tumors in four dogs. The 4 cases of lobular hyperplasia were included in the benign tumor group, and statistical analyses were performed between malignant and benign tumor groups. Tumor volume was calculated as follows; length $\times$ width $\times$ height $\times 3.14 / 6$. There was no significant difference between the malignant (mean $\left.\pm \mathrm{SD} ; 19.9 \pm 72.9 \mathrm{~cm}^{3}\right)$ and benign $\left(3.5 \pm 18.6 \mathrm{~cm}^{3}\right)$ tumor groups (Table 2). In addition, there was no significant difference in tumor size which is the maximum diameter of the mass between the 2 groups. The $\mathrm{D} / \mathrm{W}$ was significantly greater in the malignant $(0.68 \pm 0.17)$ than benign $(0.49 \pm$ 0.15 ) tumor group (Table 2, Fig. 2). To determine the most useful threshold of $\mathrm{D} / \mathrm{W}$ to differentiate malignant from benign tumors, we calculated the sensitivity, specificity and accuracy (lesions with true-positive and true-negative/ all lesions) for each value of the D/W (Fig. 3). Diagnostic
Table 1. Histopathologic classification of 86 mammary masses in 34 dogs

\begin{tabular}{clc}
\hline \multicolumn{1}{c}{ Group } & \multicolumn{1}{c}{ Histopathologic diagnosis } & $\mathrm{n}$ \\
\hline Benign $(\mathrm{n}=70)$ & Adenoma & 44 \\
& Benign mixed mammary tumor & 22 \\
& Hyperplasia* & 4 \\
\hline Malignant $(\mathrm{n}=16)$ & Carcinoma & 16 \\
\hline
\end{tabular}

*Included in the benign tumor group in this study.

accuracy based on sensitivity and specificity was highest $(86.0 \%)$ when the $\mathrm{D} / \mathrm{W}$ value was 0.7 ; this corresponded to a sensitivity of $56.3 \%$ and a specificity of $92.9 \%$.

Of the 70 benign tumors, 52 had regular margins, 59 were oval in shape, and 58 had homogeneous internal echographic characteristics. Of the 16 malignant tumors, 14 had irregular margins, 9 were polymorphous in shape, and 9 had heterogeneous internal echographic characteristics. The chi-square test performed on ultrasonographic findings revealed significant differences in the margins, shape and internal echographic characteristic of the masses between groups. However, internal echogenicity and the posterior echographic characteristic had no significant associations between benign and malignant groups (Table 2).

The present study was designed to assess $\mathrm{D} / \mathrm{W}$ and ultrasonographic characteristics between benign and malignant mammary tumors in dogs. The $\mathrm{D} / \mathrm{W}$ of malignant tumors 
Table 2. Tumor volume, size, D/W and ultrasonographic characteristics in the benign and malignant tumor groups. $P$ values in bold are statistically significant

\begin{tabular}{|c|c|c|c|}
\hline \multirow{2}{*}{ Characteristic } & Benign & Malignant & \multirow{2}{*}{$P$ value } \\
\hline & $(\mathrm{n}=70)$ & $(\mathrm{n}=16)$ & \\
\hline Tumor volume $\left(\mathrm{cm}^{3}\right)$ & $3.5 \pm 18.6$ & $19.9 \pm 72.9$ & 0.10 \\
\hline Tumor size (mm) & $12.7 \pm 9.5$ & $15.0 \pm 12.4$ & 0.40 \\
\hline $\mathrm{D} / \mathrm{W}$ & $0.49 \pm 0.15$ & $0.68 \pm 0.17$ & $<0.01$ \\
\hline \multicolumn{4}{|l|}{ Margins } \\
\hline Regular & 52 & 2 & \\
\hline Irregular & 18 & 14 & $<0.01$ \\
\hline \multicolumn{4}{|l|}{ Shape } \\
\hline Oval & 59 & 7 & \\
\hline Polymorphous & 11 & 9 & $<\mathbf{0 . 0 1}$ \\
\hline \multicolumn{4}{|l|}{ Internal echogenicity } \\
\hline Hypoechoic & 39 & 13 & \\
\hline Isoechoic & 29 & 2 & \\
\hline Hyperechoic & 2 & 1 & 0.09 \\
\hline \multicolumn{4}{|c|}{ Internal echographic characteristic } \\
\hline Homogeneous & 58 & 7 & \\
\hline Heterogeneous & 12 & 9 & $<0.01$ \\
\hline \multicolumn{4}{|c|}{ Posterior echographic characteristic } \\
\hline Enhancement & 27 & 11 & \\
\hline Unchanged & 41 & 5 & \\
\hline Shadowing & 2 & 0 & 0.08 \\
\hline
\end{tabular}

was significant greater than that of benign tumors. Interestingly, the threshold for the differentiation of malignant from benign tumors, 0.7 , was similar to the value described in human medicine [6]. In general, benign tumors lack destructive characteristics and are often encapsulated, whereas invasive growth into surrounding tissue is a typical feature of malignant tumors [13]. These different growth mechanisms between benign and malignant tumors in breast tissue might have contributed to the higher $\mathrm{D} / \mathrm{W}$ in malignant tumors.

Malignant nodules are often characterized by poorly defined margins and irregular borders. On the other hand, benign lesions are often well differentiated from the surrounding tissue by a well-defined, circumscribed margin and tend to be round or oval [12]. In addition, irregular echogenicity may occur, because of necrosis, cyst formation, edema, hemorrhage and calcification $[10,11]$. These characteristics have been advocated as useful in distinguishing between benign and malignant nodules [14]. The ultrasonographic findings pertaining to margins, shape and internal echographic characteristic obtained in this study were similar to those described in a past study using canine mammary tumors [3]. Although hypoechogenicity and shadowing have been associated with malignancy [12], internal echogenicity and the posterior echographic characteristic obtained in this study were not useful for classification of nodules as either benign or malignant. Acoustic shadowing, which is seen behind the tumor, is the result of attenuation of the sound beam by desmoplastic host response to breast cancer, and enhancement is associated with necrosis [14]. Shadowing has previously been reported to be present in a variable percentage of malignant tumors in dogs and humans $[1,3,10,14]$. It

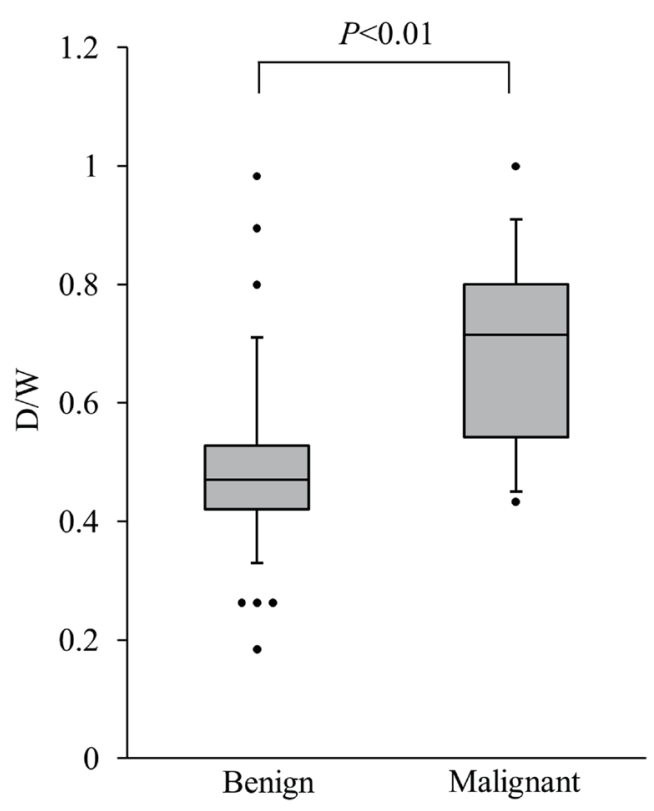

Fig. 2. Box plots of the D/W of 86 mammary masses in 34 dogs. The box represents the interquartile range (i.e., 25-75th percentile range or the middle half of the box). The horizontal bar in the box represents the median value. For both box plot, the T-bars represent the 5 to 95 percentile range. Outlying data points are represented by black dots.

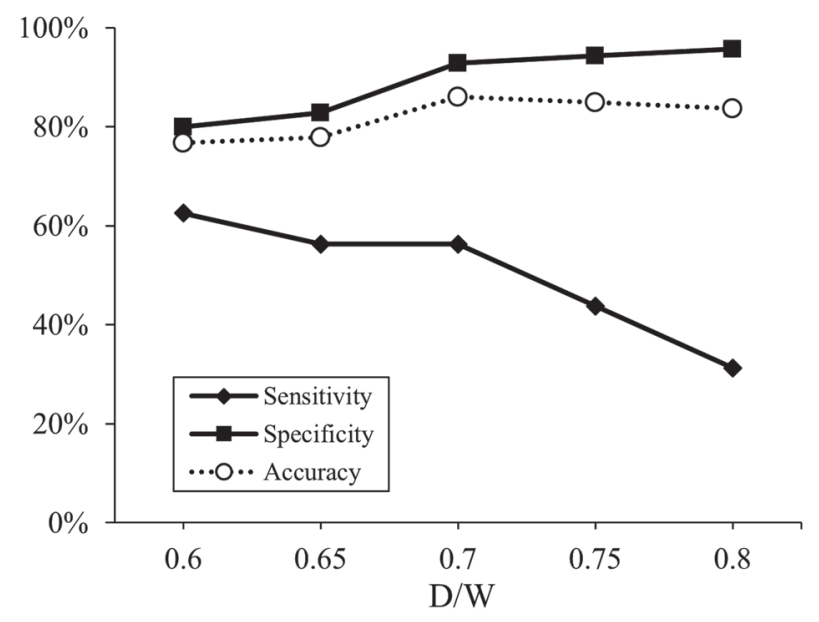

Fig. 3. The sensitivity, specificity and accuracy for each value of the $\mathrm{D} / \mathrm{W}$ of 86 mammary masses in $34 \mathrm{dogs}$.

has also been reported that some lesions present with ultrasonographic characteristics of both malignant and benign tumors $[1,9]$. In fact, some lesions obtained in this study also showed both malignant and benign ultrasonographic characteristics. Considering additional diagnostic methods, the usefulness of Doppler ultrasound has been indicated in dogs [1]. Further, in human medicine, elastography imaging, which can evaluate the elasticity of breast lesions, was supe- 
rior to sonography in differentiating benign and malignant lesions in the breast [9], and elastography has recently been performed in dogs [2]. Combinations of conventional and specialized examinations, such as those mentioned above, might increase the sensitivity of ultrasonographic diagnosis in canine mammary lesions.

In conclusion, the $\mathrm{D} / \mathrm{W}$ of malignant mammary tumors was significantly greater than that of benign tumors. In addition, certain ultrasonographic parameters could be useful for noninvasive diagnosis and differentiation between benign and malignant mammary tumors in dogs. It is considered that the $\mathrm{D} / \mathrm{W}$ is suitable for exclusion diagnosis and useful because of its quantitativity and simplicity. A further study is necessary using novel ultrasonography criteria, including $\mathrm{D} / \mathrm{W}$ and other characteristics, to increase the accuracy rate of ultrasonographic diagnosis in canine mammary tumors.

ACKNOWLEDGMENTS. We thank Dr. Daisuke Sawada, Dr. Haruna Koumoto and Dr. Jyunji Fujitsuka as well as all the animal health technicians at Kano Animal Hospital for their excellent technical assistance.

\section{REFERENCES}

1. Feliciano, M. A., Vicente, W. R. and Silva, M. A. 2012. Conventional and Doppler ultrasound for the differentiation of benign and malignant canine mammary tumours. J. Small Anim. Pract. 53: 332-337. [Medline] [CrossRef]

2. Glińska-Suchocka, K., Jankowski, M., Kubiak, K., Spuzak, J., Dzimira, S. and Nicpon, J. 2013. Application of shear wave elastography in the diagnosis of mammary gland neoplasm in dogs. Pol. J. Vet. Sci. 16: 477-482. [Medline]

3. Gonzalez de Bulnes, A., Garcia Fernandez, P., Mayenco Aguirre, A. M. and Sanchez de la Muela, M. 1998. Ultrasonographic imaging of canine mammary tumours. Vet. Rec. 143: 687-689. [Medline]

4. Honjo, S., Ando, J., Tsukioka, T., Morikubo, H., Ichimura, M., Sunagawa, M., Hasegawa, T., Watanabe, T., Kodama, T., Tominaga, K., Sasagawa, M. and Koyama, Y. 2007. Relative and combined performance of mammography and ultrasonography for breast cancer screening in the general population: a pilot study in Tochigi Prefecture, Japan. Jpn. J. Clin. Oncol. 37: 715-720. [Medline] [CrossRef]
5. Ishii, M. 1993. Ultrasonographic diagnosis of breast diseases: a review of diagnostic criteria of sonomammography on a real-time scanner. Nihon Igaku Hoshasen Gakkai Zasshi 53: 1141-1159 (in Japanese). [Medline]

6. Kato, Y., Ueno, E., Kawauchi, A., Endo, T., Kubota, M., Konishi, Y., Taniguchi, N., Tohno, E., Tsunoda, H., Yasuda, H. and Mizutani, M. 2002. Threshold value of depth width ratio (D/W) in the breast ultrasonogram. J. Med. Ultrasound 29: 450 (in Japanese).

7. Kealy, J. K. and McAllister, H. 2005. Diagnostic Radiology and Ultrasonography of the Dog and Cat, 4th ed., Saunders Elsevier, St. Louis.

8. Mohammed, S. I., Meloni, G. B., Pinna Parpaglia, M. L., Marras, V., Burrai, G. P., Meloni, F., Pirino, S. and Antuofermo, E. 2011. Mammography and ultrasound imaging of preinvasive and invasive canine spontaneous mammary cancer and their similarities to human breast cancer. Cancer Prev. Res. (Phila.) 4: 1790-1798. [Medline] [CrossRef]

9. Navarro, B., Ubeda, B., Vallespí, M., Wolf, C., Casas, L. and Browne, J. L. 2011. Role of elastography in the assessment of breast lesions: preliminary results. J. Ultrasound Med. 30: 313-321. [Medline]

10. Nyman, H. T., Nielsen, O. L., McEvoy, F. J., Lee, M. H., Martinussen, T., Hellmén, E. and Kristensen, A. T. 2006. Comparison of B-mode and Doppler ultrasonographic findings with histologic features of benign and malignant mammary tumors in dogs. Am. J. Vet. Res. 67: 985-991. [Medline] [CrossRef]

11. Paulinelli, R. R., Freitas-Júnior, R., Moreira, M. A., Moraes, V. A., Bernardes-Júnior, J. R., Vidal Cda, S., Ruiz, A. N. and Lucato, M. T. 2005. Risk of malignancy in solid breast nodules according to their sonographic features. J. Ultrasound Med. 24: 635-641. [Medline]

12. Sehgal, C. M., Weinstein, S. P., Arger, P. H. and Conant, E. F. 2006. A review of breast ultrasound. J. Mammary Gland Biol. Neoplasia 11: 113-123. [Medline] [CrossRef]

13. Sleeckx, N., de Rooster, H., Veldhuis Kroeze, E. J., Van Ginneken, C. and Van Brantegem, L. 2011. Canine mammary tumours, an overview. Reprod. Domest. Anim. 46: 1112-1131. [Medline] [CrossRef]

14. Stavros, A. T., Thickman, D., Rapp, C. L., Dennis, M. A., Parker, S. H. and Sisney, G. A. 1995. Solid breast nodules: use of sonography to distinguish between benign and malignant lesions. Radiology 196: 123-134. [Medline] [CrossRef]

15. Ueno, E., Shiina, T., Kubota, M. and Sawai, K. 2005. Research and Development in Breast Ultrasound. Springer-Verlag, Tokyo. 